\title{
BMJ Open Prevalence and predictors of alcohol use during pregnancy: findings from international multicentre cohort studies
}

\author{
Linda M O'Keeffe, ${ }^{1,2}$ Patricia M Kearney, ${ }^{2}$ Fergus P McCarthy, ${ }^{3,4}$ Ali S Khashan, ${ }^{2,3}$ \\ Richard A Greene, ${ }^{1}$ Robyn A North, ${ }^{5}$ Lucilla Poston, ${ }^{5}$ Lesley M E McCowan, ${ }^{6}$ \\ Philip N Baker, ${ }^{7}$ Gus A Dekker, ${ }^{8}$ James J Walker, ${ }^{9}$ Rennae Taylor, ${ }^{10}$ \\ Louise C Kenny ${ }^{3,4}$
}

To cite: O'Keeffe LM, Kearney PM, McCarthy FP, et al. Prevalence and predictors of alcohol use during pregnancy: findings from international multicentre cohort studies. BMJ Open 2015;5:e006323. doi:10.1136/bmjopen-2014006323

\section{- Prepublication history} and additional material is available. To view please visit the journal (http://dx.doi.org/ 10.1136/bmjopen-2014006323)

Received 7 August 2014 Revised 26 November 2014 Accepted 27 November 2014

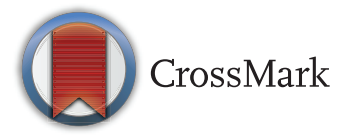

For numbered affiliations see end of article.

\section{Correspondence to} Dr Linda M O'Keeffe Cardiovascular Epidemiology Unit, University of Cambridge, Strangeways Research Laboratory, Cambridge CB1 8RN, United Kingdom; l0288@medschl.cam.ac.uk

\section{ABSTRACT \\ Objectives: To compare the prevalence and predictors of alcohol use in multiple cohorts.}

Design: Cross-cohort comparison of retrospective and prospective studies.

Setting: Population-based studies in Ireland, the UK, Australia and New Zealand.

Participants: 17244 women of predominantly Caucasian origin from two Irish retrospective studies (Growing up in Ireland (GUI) and Pregnancy Risk Assessment Monitoring System Ireland (PRAMS Ireland)), and one multicentre prospective international cohort, Screening for Pregnancy Endpoints (SCOPE) study.

\section{Primary and secondary outcome measures:}

Prevalence of alcohol use pre-pregnancy and during pregnancy across cohorts. Sociodemographic factors associated with alcohol consumption in each cohort.

Results: Alcohol consumption during pregnancy in Ireland ranged from $20 \%$ in GUI to $80 \%$ in SCOPE, and from $40 \%$ to $80 \%$ in Australia, New Zealand and the UK. Levels of exposure also varied substantially among drinkers in each cohort ranging from $70 \%$ consuming more than 1-2 units/week in the first trimester in SCOPE Ireland, to $46 \%$ and $15 \%$ in the retrospective studies. Smoking during pregnancy was the most consistent predictor of gestational alcohol use in all three cohorts, and smokers were $17 \%$ more likely to drink during pregnancy in SCOPE, relative risk (RR) $=1.17(95 \% \mathrm{Cl} 1.12$ to 1.22$), 50 \%$ more likely to drink during pregnancy in GUI, RR=1.50 $(95 \% \mathrm{Cl} 1.36$ to 1.65 ), and $42 \%$ more likely to drink in PRAMS, $\mathrm{RR}=1.42(95 \% \mathrm{Cl} 1.18$ to 1.70$)$.

Conclusions: Our data suggest that alcohol use during pregnancy is prevalent and socially pervasive in the UK, Ireland, New Zealand and Australia. New policy and interventions are required to reduce alcohol prevalence both prior to and during pregnancy. Further research on biological markers and conventions for measuring alcohol use in pregnancy is required to improve the validity and reliability of prevalence estimates.

\section{Strengths and limitations of this study}

- Our study goes beyond measurement of alcoho use during pregnancy with just one cohort or one measurement method, but examines prevalence and predictors using different measurement techniques in similar populations.

- The study had a large sample size of almost 18000 women, and we were able to examine prevalence using different modes of administration (anonymised, self-administered, postal survey, trained government interview, antenatal midwife-collected data) and timing of administration including prospective and retrospective measurement.

- However, because we relied on self-reported alcohol consumption, reporting and recall biases may exist in our study. Furthermore, differences in mode and timing of data collection could explain variation in estimates between studies.

- Our analysis only included live born babies, and thus, there is a possibility that we have excluded women with the heaviest drinking patterns, since failure to give birth to a baby could have resulted from heavy alcohol consumption; for example, miscarriage occurring due to chronic alcohol use or binge drinking in early pregnancy.

- Participants in our study may also be more advantaged than the general population, and thus, the generalisability of our findings to all pregnancies, or more diverse populations, may be reduced.

\section{INTRODUCTION}

Worldwide, the majority of clinical and government guidelines advocate for pregnant women to abstain from alcohol consumption during pregnancy due to potential adverse effects on pregnancy outcomes. ${ }^{1-4}$ However, although the National Institute of Health and Care Excellence (NICE) guidelines in the UK advise abstinence from alcohol in 
early pregnancy due to increased risk of miscarriage, it is noted that 1-2 units up to twice per week have not been shown to be harmful to the unborn baby, if women choose to drink. ${ }^{5}$

Conflicting results on the effects of gestational alcohol consumption on offspring health outcomes and subsequently, lack of coherence in clinical and government guidelines stem from a lack of biological markers of light or moderate alcohol use during pregnancy. Thus, studies of associations with offspring health outcomes rely on self-reported maternal alcohol consumption which may be biased by reporting and recall biases. For example, estimates of prevalence of alcohol use during pregnancy and its associated predictors in existing cohort data are highly variable and range from $36 \%$ in the Millennium Cohort Study $(\mathrm{MCS})^{6}$ to almost $60 \%$ in the Avon Longitudinal Study of Parents and Children (ALSPAC). ${ }^{7}$ Consequently, whether exposure and its predictors are reliably measured in observational studies is difficult to decipher, and thus, approaches which reveal the validity and reliability of estimates and predictors are required.

Cross-cohort comparisons may be a useful way to examine plausible and valid self-reported prevalence estimates and predictors. Comparing multiple cohort estimates within the same population allows the validity of prevalence estimates and predictors of alcohol use to be compared when measured using different techniques; if prevalence is accurately reported and not subject to substantial recall and reporting biases, prevalence and predictors should be mostly consistent across studies. Comparing subpopulation estimates within the same cohort allows for population variation in alcohol prevalence and predictors to be compared when exposure measurement is constant; if prevalence and predictors vary substantially across countries within the same study using the same measurement methods, insights into the impact of culture and attitudes on alcohol consumption, or reporting of alcohol, can be revealed. Taken together, such techniques may provide increased insight into plausible prevalence estimates of alcohol use during pregnancy, improved alcohol exposure measurement during pregnancy, and increased understanding of the social patterns of alcohol use across cohorts. In turn, this evidence can be used to inform antenatal care guidelines on alcohol use.

The objectives of this study were to compare the prevalence of alcohol use across three cohorts; Growing up in Ireland (GUI), ${ }^{8} 9$ Screening for Pregnancy Endpoints (SCOPE) study $^{10}$ and Pregnancy Risk Assessment Monitoring System (PRAMS) Ireland. ${ }^{11}$ GUI and PRAMS measured gestational alcohol use retrospectively, while SCOPE obtained measures of alcohol use during pregnancy. Second, we compared the characteristics associated with alcohol use in all three studies and within SCOPE countries (New Zealand, Ireland, Australia and the UK) in order to examine cross-cohort and cross-country consistency in the prevalence and predictors of gestational alcohol use.

\section{METHODS}

\section{Study population}

Growing up in Ireland

The National Longitudinal Study of Children is the first longitudinal study of its kind that focuses on the developmental trajectories of children in Ireland. ${ }^{8}$ Participants were sampled from the state child benefit register (>20000 primary care givers sampled from approximately 41000 on the register over the period 1 December 2007 to 30 June 2008) using a simple systematic selection procedure prestratifying by parental marital status, country of residence, nationality and number of children. ${ }^{8}$ Surveys were completed with the primary and secondary caregivers of 11134 infants aged 6-9 months, from September 2008 to April 2009. ${ }^{8}$ This represented almost a quarter of all births in Ireland over that period. ${ }^{8}$ Surveys were administered by trained study personnel in the home of the caregivers through a face-to-face interview. ${ }^{8}$ Non-biological mothers or male primary caregivers who participated in the study were excluded from the present analysis $(0.3 \%)$. Biological mothers who did not complete the questionnaire were also excluded from the present study $(0.1 \%)$. All participants gave informed consent prior to participation in the study.

\section{Screening for Pregnancy Endpoints}

SCOPE is a prospective, multicentre cohort study with the principal aim of developing screening tests to predict pre-eclampsia, small for gestational age (SGA) infants, and spontaneous preterm birth. ${ }^{10}$ Participants were healthy nulliparous females with singleton pregnancies $(\mathrm{n}=8531$ originally approached to participate) of which 5628 were recruited between November 2004 and February 2011 in Auckland, New Zealand; Adelaide, Australia; Cork, Ireland; and Manchester, Leeds and London, UK, as previously described. ${ }^{10}{ }^{12}$ Women were excluded if they were considered at high risk of preeclampsia, delivery of a SGA infant, or spontaneous preterm birth, because of underlying medical conditions, gynaecological history, three or more previous miscarriages, three or more terminations of pregnancy, or had received interventions, such as aspirin, that might modify pregnancy outcome. ${ }^{10}$ Study participants were interviewed and examined by study research midwives at 15 and 20 weeks of gestation. At the time of interview, data were entered on an internet-accessed central database with a complete audit trail (MedSciNet). ${ }^{13}$ Pregnancy information and pregnancy outcome data were collected prospectively by research midwives. All data entries were individually checked (including data entry errors in the lifestyle questionnaire), and a customised software program was used to detect any systematic data entry errors. All participants gave informed consent prior to participation in the study. Only participants who delivered a live born baby were included in the present analysis. 
PRAMS Ireland

The aim of PRAMS was to measure the prevalence of a wide range of maternal health behaviours and experiences before, during and after pregnancy. The sample for the study was derived using hospital discharge records of live births at Cork University Maternity Hospital, a large urban obstetric hospital in the South of Ireland where almost 9000 live births per year occur. A constant sampling fraction of 1 in 2 records alternately sampled 1212 from a sampling frame of approximately 2450 mother-infant pairs discharged between 14 May 2012 and 18 August 2012. Of these, 718 (61\%) women responded and were included in the present analysis. Mothers of stillbirths, neonatal deaths $(n=3)$ and early and late miscarriages were planned exclusions (none identified), as the objective of the study was to characterise maternal behaviours and experiences in women with live births. Women were invited to participate by post and were sent three postal surveys, a reminder letter and a text reminder. The PRAMS questionnaire was based on PRAMS Phase 6 questions covering sociodemographics, health behaviours and experiences before, during and after pregnancy, ${ }^{14}$ and detailed information on dose, pattern and timing of alcohol exposure for the 3 months before pregnancy, and in each trimester was based on the work of O'Leary et al, 2009, and described in detail elsewhere. ${ }^{11} 15$ On date of receipt of the first survey, mothers were between 2 and 5 months postpartum. On the date of receipt of the final PRAMS survey, mothers were between 7 and 9 months postpartum. Thus, respondents of the survey were anywhere between 2 and 9 months postpartum. PRAMS used an opt-out consent system whereby women who did not wish to participate in the survey were permitted to opt out at the beginning of the study. Women who did not opt out were treated as willing participants.

\section{Assessment of alcohol}

Growing up in Ireland

Women were asked, separately, if they drank in each trimester of pregnancy. Women who reported alcohol use during pregnancy were asked how much on average they drank per week ( pints of beer or cider, glasses of wine, measures of spirits or alcopops) in each trimester.

\section{Screening for Pregnancy Endpoints}

Alcohol consumption was reported as units consumed per week. At the 15-week interview, participants were asked 'Were you drinking alcohol prior to pregnancy?', 'Were you drinking alcohol earlier in the pregnancy in the first trimester?' and finally 'Are you still drinking alcohol?'. If the participants answered 'yes' to any of the above, the amount of alcohol was then quantified including number of units and binges per week. Participants who confirmed that they had consumed alcohol during pregnancy were asked when they stopped drinking. At 20 weeks' gestation, women were asked the number of units of alcohol per week consumed at
20 weeks' gestation and the number of binges taken between the 15-week and 20-week interviews.

\section{Pregnancy risk assessment monitoring system}

Women were asked to report the number of occasions per week or month alcohol was consumed ranging from never, less than 1 occasion per month, 1-2 occasions per month, 1-2 occasions per week, 3-4 occasions per week and 5 or more occasions per week for the 3 months before pregnancy, and each trimester separately. For the number of occasions indicated in each time period, women were asked to indicate the number of glasses or bottles of beer, wine $(100 \mathrm{~mL})$, alcopop, sherry or port, and spirits or liqueurs consumed per occasion.

\section{Comparing and categorising alcohol use}

Although the measurement of alcohol use during pregnancy varied across the studies, we standardised classification across each cohort to ensure categories in each study were comparable (note that some findings on alcohol use in PRAMS and SCOPE have been published previously using different category definitions and in less detail than explored here).$^{15}{ }^{16}$ For this study, one unit of alcohol was equivalent to approximately $8-10 \mathrm{~g}$ of absolute alcohol (slight variation across studies) equating to one glass of wine (approximately 100-125 mL), one small glass of sherry, a single nip of spirits, or half a pint of lager (regular strength). A can or small bottle/glass of regular-strength beer (300-330 mL, 4-5\% alcohol) was equivalent to 1.5 units of alcohol, and a bottle of alcohol pop was equivalent to 2 units of alcohol. Where prepregnancy alcohol consumption was reported, it was defined as consumption of any alcohol in the 3 months prior to pregnancy. Where quantity of alcohol before pregnancy and by trimester was available, alcohol intake was classified as occasional (1-2 units/week), low (37 units/week), moderate (8-14 units/week) and heavy (greater than 14 units/week). Median units of exposure were calculated since alcohol is not normally distributed. Binge consumption was defined as six or more standard units per occasion.

In GUI and PRAMS, any alcohol consumption or any binge consumption was defined as consumption of alcohol in the first, second or third trimester, or consumption of a binge in any of the trimesters (note, binge alcohol consumption data not available in GUI). Binge alcohol use by trimester was defined as any binge alcohol use in the first, second or third trimester separately. Alcohol use before pregnancy was not available in GUI. In SCOPE, any alcohol consumption included any alcohol consumed from conception up to the 20-week interview, including any binge consumption. First trimester use was reported at the 15-week SCOPE visit. For second trimester use, consumption in the week preceding the 15-week SCOPE visit and preceding the 20-week SCOPE visit, were combined and divided by two to obtain a weekly average consumption which was subsequently categorised as occasional, low, moderate or 
heavy, as described. Binge drinking in the second trimester was defined as reporting a binge in the week prior to the 15-week SCOPE visit, or between the 15-week and 20-week SCOPE visit.

\section{Statistical analysis}

We examined the association between low birth weight and preterm birth (traditionally examined in relation to the effects of gestational alcohol use) and common confounders of these associations and alcohol use during pregnancy (including age, ethnicity, education, marital status, parity, body mass index (BMI), smoking) since these are characteristics by which social behaviours such as alcohol use are often patterned, and characteristics which are commonly examined as predictors of alcohol use. In all analyses, covariates (age, education, ethnicity, marital status, parity, delivery mode, smoking, BMI, preterm birth and birth weight) were categorised in an identical manner for comparability (see table 1 for categories).

All statistical analyses were conducted in Stata V.12. We used frequencies to describe the characteristics of each cohort and compare reported drinking in all three studies and across SCOPE countries. We used log linear binomial regression to examine the relative risk of alcohol consumption during pregnancy in relation to sociodemographic characteristics in each cohort and in each SCOPE country. Log linear binomial regression was chosen because when an outcome variable is common $(>5 \%)$, logistic regression tends to overestimate the association between the independent variable of interest and the outcome. In GUI, as age appeared to have a

Table 1 Characteristics of women participating in GUI (2008, 2009), SCOPE Ireland (2008-2011) and PRAMS Ireland (2012) by their pregnancy alcohol consumption

\begin{tabular}{|c|c|c|c|c|c|c|c|c|c|}
\hline & \multirow{2}{*}{\multicolumn{2}{|c|}{$\begin{array}{l}\text { GUI } \\
n=10953 \\
\text { Alcohol }\end{array}$}} & \multirow[b]{3}{*}{ p Value } & \multirow{2}{*}{\multicolumn{2}{|c|}{$\begin{array}{l}\text { SCOPE Ireland } \\
\mathrm{n}=1766 \\
\text { Alcohol }\end{array}$}} & \multirow[b]{3}{*}{ p Value } & \multirow{2}{*}{\multicolumn{2}{|c|}{$\begin{array}{l}\text { PRAMS } \\
n=718 \\
\text { Alcohol }\end{array}$}} & \multirow[b]{3}{*}{ p Value } \\
\hline & & & & & & & & & \\
\hline & $\begin{array}{l}\text { Yes } \\
n=2198\end{array}$ & $\begin{array}{l}\text { No } \\
n=8755\end{array}$ & & $\begin{array}{l}\text { Yes } \\
n=1444\end{array}$ & $\begin{array}{l}\text { No } \\
n=322\end{array}$ & & $\begin{array}{l}\text { Yes } \\
n=324\end{array}$ & $\begin{array}{l}\text { No } \\
n=394\end{array}$ & \\
\hline \multicolumn{10}{|l|}{ Age (years) } \\
\hline$<20$ & 19 (10) & $169(90)$ & \multirow[t]{5}{*}{$<0.001$} & 30 (82) & 7 (18) & \multirow[t]{5}{*}{0.3} & $2(50)$ & $2(50)$ & \multirow[t]{5}{*}{0.01} \\
\hline $20-24$ & 130 (13) & 908 (87) & & 137 (83) & 29 (17) & & 4 (17) & 19 (83) & \\
\hline $25-29$ & 337 (15) & 1938 (85) & & $433(80)$ & $110(20)$ & & 53 (38) & 85 (62) & \\
\hline $30-39$ & 1528 (23) & $5046(77)$ & & 828 (83) & 164 (17) & & 248 (49) & $255(51)$ & \\
\hline$>40$ & 184 (27) & 500 (73) & & $16(73)$ & $6(27)$ & & 17 (44) & $22(56)$ & \\
\hline \multicolumn{10}{|l|}{ Education } \\
\hline Second & 727 (15) & 4004 (85) & \multirow[t]{2}{*}{$<0.001$} & $1286(82)$ & 279 (18) & \multirow[t]{2}{*}{0.7} & 47 (40) & $72(60)$ & \multirow[t]{2}{*}{0.1} \\
\hline Tertiary & 1470 (24) & 4551 (76) & & 158 (81) & 37 (19) & & 277 (47) & 307 (53) & \\
\hline \multicolumn{10}{|l|}{ Ethnicity } \\
\hline Caucasian & $2160(22)$ & 7868 (78) & \multirow[t]{2}{*}{$<0.001$} & 1433 (83) & 286 (17) & \multirow[t]{2}{*}{$<0.001$} & $316(47)$ & $253(53)$ & \multirow[t]{2}{*}{$<0.01$} \\
\hline Other & $36(5)$ & 657 (95) & & 11 (27) & $30(73)$ & & 3 (10) & $26(90)$ & \\
\hline \multicolumn{10}{|l|}{ Marital status } \\
\hline Married & $1644(22)$ & $6021(78)$ & \multirow[t]{2}{*}{$<0.001$} & $1277(81)$ & 296 (19) & \multirow[t]{2}{*}{$<0.01$} & $306(46)$ & $355(54)$ & \multirow[t]{2}{*}{0.4} \\
\hline Single & 554 (18) & 2540 (82) & & 167 (89) & 20 (11) & & 18 (39) & $28(61)$ & \\
\hline \multicolumn{10}{|l|}{ Parity } \\
\hline 0 & 760 (18) & 3401 (82) & \multirow[t]{2}{*}{$<0.001$} & 1450 (82) & 318 (18) & - & $128(46)$ & $151(54)$ & \multirow[t]{2}{*}{0.97} \\
\hline $1+$ & 1438 (22) & $5160(78)$ & & - & - & - & $194(46)$ & $230(54)$ & \\
\hline \multicolumn{10}{|l|}{ Smoking } \\
\hline Yes & 445 (24) & $1386(76)$ & \multirow[t]{2}{*}{$<0.001$} & 448 (92) & $38(8)$ & $<0.001$ & 77 (55) & $63(45)$ & 0.01 \\
\hline No & 1753 (20) & 7174 (80) & & $996(78)$ & 279 (22) & & $204(43)$ & 272 (57) & \\
\hline BMI $\left(\mathrm{kg} / \mathrm{m}^{2}\right)$ & & & & & & & & & \\
\hline$<18.5$ & 52 (18) & 232 (82) & $<0.001$ & $838(81)$ & 194 (19) & 0.2 & $9(36)$ & $16(64)$ & 0.5 \\
\hline $18.5-24.99$ & 1143 (22) & 4132 (78) & & 17 (82) & 4 (18) & & $220(48)$ & 237 (52) & \\
\hline 25.0-29.9 & $626(21)$ & 2402 (79) & & 419 (85) & 74 (15) & & 69 (46) & $81(54)$ & \\
\hline$>30$ & 275 (17) & 1376 (83) & & 170 (79) & $44(21)$ & & 21 (41) & 31 (59) & \\
\hline Preterm birth & & & & & & & & & \\
\hline Yes & $113(16)$ & 585 (84) & $<0.01$ & 67 (79) & $18(21)$ & 0.4 & $15(41)$ & $22(60)$ & 0.5 \\
\hline No & 2081 (21) & 7947 (79) & & 1377 (82) & 298 (18) & & 309 (46) & $360(54)$ & \\
\hline Birth weight & & & & & & & & & \\
\hline$<2500 \mathrm{~g}$ & $86(15)$ & $500(85)$ & $<0.001$ & $1384(82)$ & 302 (18) & 0.8 & $14(38)$ & 310 (62) & 0.3 \\
\hline$>/=2500 \mathrm{~g}$ & 2095 (21) & 7963 (79) & & 60 (81) & 14 (19) & & $23(46)$ & $360(54)$ & \\
\hline
\end{tabular}

All differences tested with $\chi^{2}$ test for categorical variables.

BMI, body mass index; GUI, Growing up in Ireland; PRAMS, Pregnancy Risk Assessment Monitoring System; SCOPE, Screening for Pregnancy Endpoints. 
linear effect on alcohol, we repeated the model without specifying age as categorical variable to examine a potential trend in the association between age and alcohol use. In the analysis of SCOPE countries, UK centres (Manchester, Leeds and London) were combined. All participants provided written informed consent.

\section{RESULTS}

Eleven thousand one hundred and thirty-four participants were recruited to the GUI study of which 10953 were included in the present analysis after exclusion of male primary caregivers and women who did not answer the sensitive questionnaire. Five thousand five hundred and seventy-three participants with live births in SCOPE were included (99\% of total cohort), 1766 of which occurred in SCOPE Ireland. All PRAMS ( $\mathrm{n}=718)$ respondents were included in the analysis.

Online supplementary table S1 describes the overall participant characteristics of each study. Table 1 shows reporting of alcohol use by sociodemographics in each cohort. In addition to the marked variation in reporting of alcohol use across cohorts, reporting of alcohol use varied considerably across sociodemographics and health characteristics in each cohort. For example, there was evidence of strong social gradients in alcohol consumption for all characteristics in GUI which were not apparent in SCOPE and PRAMS.

SCOPE had the highest overall reported prevalence of alcohol both pre-pregnancy (90\% vs 77\% in PRAMS) and during pregnancy (82\% vs $46 \%$ in PRAMS) (table 2). GUI reported the lowest overall consumption of alcohol use during pregnancy at 20\%. SCOPE participants also reported the highest overall consumption levels both prepregnancy and during pregnancy, and the highest binge consumption before (59\%) and during pregnancy $(45 \%)$. By the second trimester, reported prevalence and reported consumption levels in SCOPE (29\%) were almost equal to PRAMS (31\%). Examining changes between the first and second trimesters, SCOPE alcohol prevalence dropped from $82 \%$ to $29 \%$ consumption between the first and second trimesters, although PRAMS and GUI alcohol consumption stayed relatively constant across all three trimesters at 30\% in PRAMS and $10-15 \%$ in GUI. Additionally, among the SCOPE participants who continued to drink in the second trimester, there were also substantial reductions in the levels of drinking $(70 \%$ drinking greater than 1-2 units/week in the first trimester compared with $2 \%$ in the second trimester).

Table 3 shows the characteristics associated with alcohol consumption in each cohort. Compared with Caucasian ethnicities, non-Caucasian women in all cohorts were less likely to drink alcohol during pregnancy. Smoking was related to greater risk of consuming alcohol during pregnancy in all three cohorts (RR range from 1.17 to 1.50 for the three cohorts). Younger age was related to lower risk of alcohol use in GUI, and women aged greater than 39 years were more likely to drink alcohol during pregnancy compared with women aged 30-39 years; with evidence of a linear association, overall, between age and gestational alcohol use ( $p$ value for trend $<0.05$ ) in GUI. Having a second-level education, being multiparous, and having a BMI $>30$ were related to lower risk of alcohol use during pregnancy in GUI. In SCOPE, single women were more likely to drink alcohol during pregnancy. In relation to outcomes commonly examined in relation to the effects of gestational alcohol use, delivery of a low birth weight infant was not associated with alcohol use in SCOPE; however, in both retrospective cohorts, we found evidence that women who delivered low birth weight infants were less likely to drink alcohol (albeit with CIs spanning the null). For preterm birth, we did not find strong evidence of an association with alcohol use in any of the three cohorts.

Table 4 shows the distribution of alcohol use across each of the four participating countries in SCOPE where $\log$ linear binomial regression was used to examine the characteristics associated with alcohol consumption in each cohort adjusted for other variables in the table. Reported alcohol use before and during pregnancy was high in all centres $(>40 \%)$, but prevalence and quantity of consumption varied substantially by SCOPE centre ( $p<0.05$ for differences in all indices of pre-pregnancy and early pregnancy alcohol consumption). Ireland had the highest prevalence of any alcohol consumption prepregnancy $(90 \%)$ and during pregnancy $(82 \%)$, and the highest reported binge consumption before $(59 \%)$ and during (45\%) pregnancy. Reported alcohol consumption dropped substantially for all countries in the second trimester as did reported binge consumption. In multivariate $\log$ linear binomial regression, factors associated with alcohol use consistently in each SCOPE centre were smoking during pregnancy (all countries) and ethnicity (Ireland, the UK and New Zealand). Other factors that were related to alcohol use but less consistently so, were age, marital status and education (New Zealand Centre only) (table 5 ).

\section{DISCUSSION}

Our findings show a high prevalence of alcohol use during pregnancy (ranging from $20 \%$ to $80 \%$ in Ireland), from $40 \%$ upwards in the UK, Australia and New Zealand, and high levels of binge drinking during pregnancy (in excess of $45 \%$ in the Irish centre of the SCOPE cohort). These findings illustrate low adherence to alcohol guidelines advising complete abstinence from alcohol during pregnancy in Ireland, ${ }^{1}$ New Zealand ${ }^{2}$ and Australia, and NICE guidelines in the UK advising consumption of no more than 1-2 units once or twice per week. ${ }^{5}$ We found that this high prevalence was, in general, pervasive across all social groups, and of the predictors of alcohol consumption examined, smoking 
Table 2 Prevalence of alcohol consumption in GUI $(2008,2009)$, SCOPE Ireland (2008-2011) and PRAMS Ireland (2012)

\begin{tabular}{|c|c|c|c|}
\hline & $\begin{array}{l}\text { GUI } \\
n=10953 \\
n(\%)\end{array}$ & $\begin{array}{l}\text { SCOPE Ireland } \\
n=1766 \\
n(\%)\end{array}$ & $\begin{array}{l}\text { PRAMS } \\
\mathrm{n}=718 \\
\mathrm{n}(\%)\end{array}$ \\
\hline Pre-pregnancy alcohol consumption & Not recorded & $1586(90)$ & $545(77)$ \\
\hline Non-drinkers pre-pregnancy & Not recorded & $180(10)$ & $173(23)$ \\
\hline \multicolumn{4}{|l|}{ Severity of consumption (units/week)* } \\
\hline $1-2$ & Not recorded & $287(18)$ & $168(43)$ \\
\hline $3-7$ & Not recorded & $602(38)$ & $96(24)$ \\
\hline $8-14$ & Not recorded & $451(28)$ & 73 (19) \\
\hline$>14$ & Not recorded & $247(16)$ & $58(15)$ \\
\hline Median (IQR) & Not recorded & $6(3,11)$ & $4(1,10$ \\
\hline Pre-pregnancy binging & Not recorded & $1044(59)$ & $134(24)$ \\
\hline Any alcohol in pregnancy & $2198(20)$ & $1444(82)$ & $325(46)$ \\
\hline Non-drinkers in pregnancy & $8755(80)$ & $322(18)$ & $383(54)$ \\
\hline Binge (any in pregnancy) & Not recorded & $795(45)$ & $23(4)$ \\
\hline First trimester alcohol consumption & $1127(11)$ & $1415(80)$ & $211(30)$ \\
\hline Non-drinkers in first trimester & $9826(89)$ & $351(20)$ & $507(70)$ \\
\hline \multicolumn{4}{|l|}{ Severity of consumption (units/week) ${ }^{\star}$} \\
\hline $1-2$ & $572(54)$ & $424(30)$ & $142(85)$ \\
\hline $3-7$ & $332(31)$ & $600(42)$ & $11(7)$ \\
\hline $8-14$ & $117(11)$ & 266 (19) & $8(5)$ \\
\hline$>14$ & $41(4)$ & $125(9)$ & $7(4)$ \\
\hline Median (IQR) & $2(2,2)$ & $4(2,7.5)$ & $1(1,2)$ \\
\hline Binge first trimester (yes) & Not recorded & $795(45)$ & $21(3)$ \\
\hline Second trimester alcohol consumption & $1585(15)$ & $500(29)$ & $216(31)$ \\
\hline Non-drinkers in second trimester & $9368(85)$ & $1266(71)$ & $502(69)$ \\
\hline \multicolumn{4}{|l|}{ Severity of consumption (units/week) ${ }^{\star}$} \\
\hline $1-2$ & $1006(66)$ & $486(98)$ & $153(91)$ \\
\hline $3-7$ & $367(25)$ & $11(2)$ & $10(6)$ \\
\hline $8-14$ & $93(6)$ & $1(0.2)$ & $5(3)$ \\
\hline$>14$ & $23(2)$ & 0 & $1(1)$ \\
\hline Median (IQR) & $1(1,2)$ & $0.5(0.3,1.0)$ & $1(1,1)$ \\
\hline Binge second trimester (yes) & Not recorded & $7(0.4)$ & $4(1)$ \\
\hline Third trimester alcohol consumption & $1559(14)$ & Not recorded & 225 (32) \\
\hline Non-drinkers in third trimester & $9394(84)$ & No recorded & $493(68)$ \\
\hline \multicolumn{4}{|l|}{ Severity of consumption (units/week) ${ }^{\star}$} \\
\hline $1-2$ & $1016(70)$ & Not recorded & $161(90)$ \\
\hline $3-7$ & $341(23)$ & Not recorded & $13(7)$ \\
\hline $8-14$ & $78(5)$ & Not recorded & $4(2)$ \\
\hline$>14$ & $21(1)$ & Not recorded & $1(1)$ \\
\hline Median (IQR) & $1(1,2)$ & Not recorded & $1(1,1)$ \\
\hline Binge third trimester (yes) & Not recorded & Not recorded & $6(1)$ \\
\hline
\end{tabular}

${ }^{*}$ Note that severity of alcohol consumption only refers to women who consumed alcohol during pregnancy.

GUI, Growing up in Ireland; PRAMS, Pregnancy Risk Assessment Monitoring System; SCOPE, Screening for Pregnancy Endpoints.

was the only consistent predictor of alcohol use across all cohorts and countries examined.

To the best of our knowledge, this is the first crosscohort comparison of the prevalence and predictors of alcohol use during pregnancy. Our study goes beyond measurement of alcohol use during pregnancy with just one cohort or one measurement method, but examines prevalence and predictors using different measurement techniques in the same population. It also examines variation in prevalence keeping measurement constant across different settings. The study had a large sample size of almost 18000 women. We were able to examine prevalence using different modes of administration (anonymised self-administered postal survey in PRAMS, trained government interview in GUI, antenatal midwifecollected data in SCOPE) and timing of administration (2-9 months postpartum in PRAMS, 9-12 months postpartum in GUI, and in the second trimester of pregnancy in SCOPE). However, as we used self-reported alcohol consumption data, reporting and recall biases may exist, and where the true estimate lies (ranging from 20\% in GUI to $80 \%$ in SCOPE) is unclear. Our findings of reduced alcohol consumption in women who had low birth weight infants in both the retrospective studies may suggest differential recall bias among women with adverse birth outcomes, since similar evidence was not 
Table 3 Log linear binomial regression for risk of alcohol during pregnancy

\begin{tabular}{|c|c|c|c|}
\hline & $\begin{array}{l}\text { GUI } \\
\mathrm{n}=10953 \\
\text { Adjusted RR } \\
(95 \% \mathrm{Cl})\end{array}$ & $\begin{array}{l}\text { SCOPE Ireland } \\
\mathrm{n}=1766 \\
\text { Adjusted RR } \\
(95 \% \mathrm{Cl})\end{array}$ & $\begin{array}{l}\text { PRAMS } \\
\mathrm{n}=718 \\
\text { Adjusted RR } \\
(95 \% \mathrm{Cl})\end{array}$ \\
\hline \multicolumn{4}{|l|}{ Age (years) } \\
\hline$<20$ & $0.48(0.30$ to 0.77$)$ & $0.92(0.85$ to 1.00$)$ & $1.31(0.42$ to 4.14$)$ \\
\hline $20-24$ & $0.56(0.46$ to 0.68$)$ & 0.84 (0.71 to 0.99$)$ & $0.26(0.09$ to 0.77$)$ \\
\hline $25-29$ & 0.69 (0.62 to 0.78$)$ & 0.95 (0.91 to 1.00$)$ & $0.84(0.66$ to 1.08$)$ \\
\hline 30-39 & Reference & Reference & Reference \\
\hline$>40$ & $1.18(1.04$ to 1.35$)$ & 0.86 (0.66 to 1.10$)$ & 0.97 (0.67 to 1.39$)$ \\
\hline \multicolumn{4}{|l|}{ Education* } \\
\hline Secondary & 0.65 (0.60 to 0.72$)$ & 0.94 (0.88 to 1.01$)$ & 0.81 (0.62 to 1.07$)$ \\
\hline Tertiary & Reference & Reference & Reference \\
\hline \multicolumn{4}{|l|}{ Ethnicity } \\
\hline Caucasian & Reference & Reference & Reference \\
\hline Other & $0.27(0.19$ to 0.37$)$ & $0.34(0.20$ to 0.56$)$ & $0.31(0.11$ to 0.88$)$ \\
\hline \multicolumn{4}{|l|}{ Marital status } \\
\hline Married & Reference & Reference & Reference \\
\hline Single & 1.05 (0.96 to 1.17$)$ & 1.09 (1.02 to 1.17$)$ & $0.98(0.65$ to 1.47$)$ \\
\hline \multicolumn{4}{|l|}{ Parity } \\
\hline 0 & Reference & - & Reference \\
\hline $1+$ & 0.90 (0.83 to 0.98$)$ & - & $1.02(0.86$ to 1.21$)$ \\
\hline \multicolumn{4}{|l|}{ Smoking } \\
\hline Yes & $1.50(1.36$ to 1.65$)$ & 1.17 (1.12 to 1.22$)$ & $1.42(1.18$ to 1.70$)$ \\
\hline No & Reference & Reference & Reference \\
\hline \multicolumn{4}{|l|}{ BMI $\left(\mathrm{kg} / \mathrm{m}^{2}\right)$} \\
\hline$<18.5$ & $1.01(0.79$ to 1.29$)$ & $1.06(0.86$ to 1.30$)$ & $0.80(0.46$ to 1.41$)$ \\
\hline $18.5-24.99$ & $0.98(0.90$ to 1.07$)$ & 1.02 (0.97 to 1.07$)$ & $0.96(0.78$ to 1.18$)$ \\
\hline 25.0-29.9 & Reference & Reference & Reference \\
\hline$>30$ & $0.84(0.74$ to 0.94$)$ & $0.96(0.89$ to 1.04$)$ & $0.89(0.63$ to 1.27$)$ \\
\hline \multicolumn{4}{|c|}{ Low birth weight $(<2500 \mathrm{~g})$} \\
\hline No & Reference & Reference & Reference \\
\hline Yes & $0.76(0.60$ to 0.96$)$ & $1.01(0.89$ to 1.14$)$ & $0.66(0.36$ to 1.22$)$ \\
\hline \multicolumn{4}{|c|}{ Preterm birth (<37 weeks gestation) } \\
\hline No & Reference & Reference & Reference \\
\hline Yes & $0.91(0.74$ to 1.12$)$ & $0.94(0.83$ to 1.07$)$ & $0.97(0.56$ to 1.66$)$ \\
\hline \multicolumn{4}{|c|}{$\begin{array}{l}\text { Log linear binomial regression was used to examine the characteristics associated with alcohol consumption in each cohort and adjusted for } \\
\text { all variables in table. } \\
\text { *Secondary includes all education up to university or post school institutions. Tertiary includes any tertiary education at a university or other } \\
\text { post school institution. } \\
\text { BMI, body mass index; GUI, Growing up in Ireland; PRAMS, Pregnancy Risk Assessment Monitoring System; SCOPE, Screening for } \\
\text { Pregnancy Endpoints. }\end{array}$} \\
\hline
\end{tabular}

found in the prospective SCOPE cohort where data was collected concurrently before women knew the outcome of their pregnancy. Estimates of prevalence may vary across the studies, in part, due to methodological differences in the assessment of alcohol related to the nature, content and timing of questions. The interaction of these methodological differences with a participant's desire to report in a socially desirable way may also explain variation in reporting across studies. For example, in the GUI cohort, women may have under-reported to a greater extent due to the influence of social desirability in the presence of a trained government interviewer. This contrasts with potentially better reporting of alcohol consumption in the anonymised PRAMS postal questionnaire. Therefore, variation in prevalence across the cohorts is likely to be driven by sociodemographic differences in the cohorts which influence true consumption levels, as well as measurement and reporting differences across the studies. Additionally, we have only included live born babies in our analysis and thus, there is a possibility that we have excluded women with the heaviest drinking patterns, since failure to give birth to a baby could have resulted from heavy drinking; for example, miscarriage occurring due to early pregnancy chronic alcohol use or binge drinking. Participants in our studies may also be more advantaged than the general population and thus, the generalisability of our findings to all pregnancies or more diverse populations may be reduced. Nonetheless, the cross-cohort comparison improves upon previously published single cohort analyses, since it shows gestational alcohol use to be prevalent and socially pervasive during pregnancy, as 
Table 4 Comparison of alcohol use in SCOPE Centre's

\begin{tabular}{|c|c|c|c|c|c|c|}
\hline & $\begin{array}{l}\text { Total } \\
\mathrm{n}=5573\end{array}$ & $\begin{array}{l}\text { New Zealand } \\
\mathrm{n}=2006\end{array}$ & $\begin{array}{l}\text { Ireland } \\
n=1766\end{array}$ & $\begin{array}{l}\text { Australia } \\
n=1150\end{array}$ & $\begin{array}{l}U^{*} \\
n=651\end{array}$ & p Value \\
\hline Pre-pregnancy alcohol consumption & $4319(77)$ & $1552(77)$ & $1586(90)$ & $539(53)$ & $540(83)$ & $<0.001$ \\
\hline Non-drinkers pre-pregnancy & $1254(23)$ & $454(23)$ & $180(10)$ & $611(47)$ & $111(17)$ & \\
\hline \multicolumn{7}{|l|}{ Severity of consumption (units/week) $\dagger$} \\
\hline $1-2$ & $1126(26)$ & $503(32)$ & $287(18)$ & $232(38)$ & $104(19)$ & $<0.001$ \\
\hline $3-7$ & $1674(39)$ & $698(45)$ & $602(38)$ & $211(34)$ & $163(30)$ & \\
\hline $8-14$ & $963(22)$ & $253(16)$ & $451(28)$ & $94(15)$ & $165(31)$ & \\
\hline$>14$ & $528(12)$ & $98(6)$ & $246(16)$ & $76(12)$ & $108(20)$ & \\
\hline Median (IQR) & $5(2,10)$ & $4(2,7)$ & $6(3,11)$ & $4(1,8)$ & $7.5(3,13)$ & $<0.001$ \\
\hline Pre-pregnancy binging & $1741(31)$ & $337(17)$ & $1044(59)$ & $123(11)$ & $247(38)$ & $<0.001$ \\
\hline Any alcohol in pregnancy & $3482(63)$ & $1107(56)$ & $1444(82)$ & $459(40)$ & $476(75)$ & $<0.001$ \\
\hline Non-drinkers in pregnancy & $2091(37)$ & $899(44)$ & $322(18)$ & $691(60)$ & $175(25)$ & \\
\hline Binge (any in pregnancy) & $1282(23)$ & $167(9)$ & $795(45)$ & $113(10)$ & 207 (33) & $<0.001$ \\
\hline First trimester alcohol consumption & $3370(60)$ & $1063(53)$ & $1415(80)$ & $440(38)$ & $451(69)$ & $<0.001$ \\
\hline Non-drinking in first trimester & $2203(40)$ & $943(47)$ & $171(20)$ & $710(62)$ & $200(61)$ & \\
\hline \multicolumn{7}{|l|}{ Severity of consumption (units/week) $\dagger$} \\
\hline $1-2$ & $1078(32)$ & $361(34)$ & $424(30)$ & $142(32)$ & $151(34)$ & $<0.001$ \\
\hline $3-7$ & $1372(41)$ & $463(44)$ & $600(42)$ & $158(36)$ & $151(34)$ & \\
\hline $8-14$ & $624(19)$ & $175(16)$ & $266(19)$ & $80(18)$ & $103(23)$ & \\
\hline$>14$ & $296(9)$ & $65(6)$ & $125(9)$ & $60(14)$ & $46(10)$ & \\
\hline Binge first trimester & $1279(23)$ & $167(8)$ & $795(45)$ & $111(10)$ & $206(32)$ & $<0.001$ \\
\hline Median (IQR) & $4(2,8)$ & $4(2,7)$ & $4(2,7.5)$ & $5(2,10)$ & $4(1.9,9)$ & 0.020 \\
\hline Second trimester alcohol consumption & $1018(19)$ & $232(12)$ & $500(29)$ & $73(7)$ & $213(34)$ & $<0.001$ \\
\hline Non-drinking in second trimester & $4555(81)$ & $1774(88)$ & $1266(71)$ & $1077(83)$ & $438(66)$ & \\
\hline \multicolumn{7}{|l|}{ Severity of consumption (units/week) $†$} \\
\hline $1-2$ & $976(97)$ & $220(97)$ & $486(98)$ & $68(93)$ & $202(96)$ & 0.3 \\
\hline $3-7$ & $30(3)$ & $7(3)$ & $11(2)$ & $4(5)$ & $8(4)$ & \\
\hline $8-14$ & $3(0.3)$ & 0 & $1(0.2)$ & $1(1)$ & $1(0.5)$ & \\
\hline$>14$ & 0 & 0 & 0 & 0 & 0 & \\
\hline Binge second trimester & $18(0.4)$ & $2(0.1)$ & $7(0.4)$ & $6(1)$ & $3(1)$ & 0.2 \\
\hline Median (IQR) & $0.5(0.3,1)$ & $0.5(0.3,1)$ & $0.5(0.3,1)$ & $0.5(0.1,1)$ & $0.8(0.5,1.5)$ & $<0.001$ \\
\hline
\end{tabular}

measured by various measurement methods and in different settings. Second, across different studies and settings, maternal smoking is a strong and consistent predictor of alcohol consumption in pregnancy. Additionally, from a methodological perspective, the analysis points to the need for an agreed convention by which to measure gestational alcohol use to avoid substantial variation and heterogeneity in estimates and predictors of gestational alcohol use in future studies.

Our findings of a range of gestational alcohol use from 20 to $80 \%$ are largely consistent with studies of similar design for each cohort, respectively. In general, prospective ascertainment of exposure has been shown to be more accurate than retrospective reporting where it has been suggested that postpartum drinking levels and poorer memory after the fact could influence reporting. ${ }^{17}$ In the prospective SCOPE study, the high rates of pre-pregnancy and gestational alcohol consumption that were observed in Ireland are compatible with estimates from another large contemporary prospectively recruited urban Irish cohort $(\mathrm{n}=65000)$ which had a similar prospective design but with both nulliparous and multiparous participants. ${ }^{18}$ However, GUI estimates are likely to substantially underestimate gestational alcohol consumption, especially when compared with $37 \%$ alcohol prevalence in the UK MCS, a cohort of almost identical design where exposure was measured 9 months postpartum. ${ }^{6}$ Potential reasons why GUI and MCS estimates are not compatible include differences in interviewing techniques and administration of surveys which would easily influence reporting of socially undesirable behaviours such as gestational alcohol use. Alternately, the retrospective PRAMS estimate of alcohol consumption of almost $50 \%$ in pregnancy is comparable with estimates from a number of large European cohorts including Generation $\mathrm{R}^{19}$ the Danish National Birth cohort, ${ }^{20}$ $\mathrm{MCS}^{6}$ and another recent prospective cohort from Leeds in the UK. ${ }^{21}$ This suggests that the retrospective component in itself may not always result in an underestimation of alcohol use. Throughout much of the literature, it is 
Table 5 Log linear binomial regression for risk of alcohol consumption during pregnancy in SCOPE

\begin{tabular}{|c|c|c|c|c|}
\hline & $\begin{array}{l}\text { New Zealand } \\
\mathrm{n}=2006 \\
\text { Adjusted RR }(95 \% \mathrm{Cl})\end{array}$ & $\begin{array}{l}\text { Ireland } \\
\mathrm{n}=1766 \\
\text { Adjusted RR (95\% Cl) }\end{array}$ & $\begin{array}{l}\text { Australia } \\
\mathrm{n}=1150 \\
\text { Adjusted RR }(95 \% \mathrm{Cl})\end{array}$ & $\begin{array}{l}\text { UK}^{\star} \\
\mathrm{n}=651 \\
\text { Adjusted RR }(95 \% \mathrm{Cl})\end{array}$ \\
\hline \multicolumn{5}{|l|}{ Age (years) } \\
\hline$<20$ & 0.78 (0.66 to 0.93$)$ & $0.92(0.85$ to 1.00$)$ & $0.94(0.75$ to 1.17$)$ & $1.02(0.90$ to 1.16$)$ \\
\hline $20-24$ & 0.74 (0.56 to 0.97$)$ & $0.84(0.71$ to 0.99$)$ & $0.90(0.70$ to 1.16$)$ & 0.86 (0.69 to 1.07$)$ \\
\hline $25-29$ & 0.83 (0.76 to 0.91$)$ & 0.95 (0.91 to 1.00$)$ & $1.03(0.81$ to 1.30$)$ & 0.93 (0.84 to 1.03$)$ \\
\hline 30-39 & Reference & Reference & Reference & Reference \\
\hline$>40$ & $0.71(0.52$ to 0.98$)$ & $0.86(0.66$ to 1.10$)$ & $1.33(0.63$ to 2.84$)$ & $0.77(0.45$ to 1.33$)$ \\
\hline \multicolumn{5}{|l|}{ Education† } \\
\hline Secondary & $0.84(0.74$ to 0.96$)$ & $0.94(0.88$ to 1.01$)$ & $0.96(0.82$ to 1.11$)$ & $0.93(0.79$ to 1.09$)$ \\
\hline Tertiary & Reference & Reference & Reference & Reference \\
\hline \multicolumn{5}{|l|}{ Ethnicity } \\
\hline Caucasian & Reference & Reference & Reference & Reference \\
\hline Other & 0.67 (0.58 to 0.78$)$ & $0.34(0.20$ to 0.56$)$ & $0.77(0.58$ to 1.03$)$ & 0.57 (0.46 to 0.71$)$ \\
\hline \multicolumn{5}{|l|}{ Marital status } \\
\hline Married & Reference & Reference & Reference & Reference \\
\hline Single & $1.22(1.02$ to 1.46$)$ & 1.09 (1.02 to 1.17$)$ & 1.07 (0.89 to 1.29$)$ & $1.08(0.93$ to 1.26$)$ \\
\hline \multicolumn{5}{|l|}{ Smoking } \\
\hline Yes & 1.50 (1.36 to 1.66$)$ & $1.17(1.12$ to 1.22$)$ & $1.82(1.57$ to 2.11$)$ & 1.15 (1.05 to 1.27$)$ \\
\hline \multirow{2}{*}{\multicolumn{5}{|c|}{ BMI $\left(\mathrm{kg} / \mathrm{m}^{2}\right)$}} \\
\hline & & & & \\
\hline$<18.5$ & $0.88(0.55$ to 1.41$)$ & 1.06 (0.86 to 1.30$)$ & $0.76(0.47$ to 1.22$)$ & 0.67 (0.31 to 1.44$)$ \\
\hline $18.5-24.99$ & Reference & Reference & Reference & Reference \\
\hline 25.0-29.9 & 1.01 (0.93 to 1.10$)$ & $1.02(0.97$ to 1.07$)$ & $1.18(1.00$ to 1.38$)$ & $0.98(0.88$ to 1.08$)$ \\
\hline$>30$ & $0.86(0.75$ to 1.00$)$ & $0.96(0.89$ to 1.04$)$ & $0.84(0.70$ to 1.01$)$ & $0.85(0.73$ to 1.00$)$ \\
\hline \multicolumn{5}{|c|}{ Low birth weight $(<2500 \mathrm{~g})$} \\
\hline No & Reference & Reference & Reference & Reference \\
\hline Yes & $0.94(0.76$ to 1.18$)$ & $1.01(0.89$ to 1.14$)$ & $1.29(0.88$ to 1.89$)$ & $1.22(0.86$ to 1.73$)$ \\
\hline \multicolumn{5}{|c|}{ Preterm birth (<37 weeks gestation) } \\
\hline No & Reference & Reference & Reference & Reference \\
\hline Yes & $0.81(0.65$ to 1.00$)$ & 0.94 (0.83 to 1.07$)$ & $1.02(0.73$ to 1.42$)$ & $1.08(0.79$ to 1.49$)$ \\
\hline \multicolumn{5}{|c|}{$\begin{array}{l}\text { Log linear binomial regression was used to examine the characteristics associated with alcohol consumption in each cohort and adjusted for } \\
\text { all variables in table. } \\
\text { *London, Manchester, Leeds. } \\
\text { †Secondary includes all education up to university or post school institutions. Tertiary includes any tertiary education at a university or other } \\
\text { post school institution. } \\
\text { BMI, body mass index; SCOPE, Screening for Pregnancy Endpoints. }\end{array}$} \\
\hline
\end{tabular}

widely shown and accepted that face-to-face interviews are often the 'gold standard' in epidemiological research. However, in relation to more subjective issues which could be biased by social desirability, self-administered questionnaires may elicit better quality data. ${ }^{22}$ In our cross-cohort comparison, estimates of alcohol prevalence in the face-to-face GUI survey were considerably lower than in PRAMS, a finding which would support the superiority of self-administered questionnaires in measuring more subjective issues such as alcohol use. However, since reporting of other socially undesirable behaviours during the perinatal period in GUI was high (eg, 18\% of smoking in pregnancy), it is possible that low reporting of alcohol prevalence in GUI could be explained by true population differences in prevalence of alcohol use in pregnancy. Finally, our results for other SCOPE centres, such as the UK, are higher than some British birth cohorts, ${ }^{6}{ }^{7}$ but generally consistent with the high prevalence reported in other large studies, such as ALSPAC. ${ }^{7}$
SCOPE Australia and New Zealand estimates also appear to be reasonably consistent with some previous data in the region. ${ }^{23-26}$

The findings of this study have direct application to policy and practice. Alcohol use during pregnancy is highly prevalent, and evidence from this cross-cohort and cross-country comparison shows that gestational alcohol exposure may occur in over $75 \%$ of pregnancies in the UK and Ireland. Although low proportions of women engaged in heavy drinking, the adverse consequences of heavy alcohol consumption during pregnancy on birth outcomes, long-term gross motor function, ${ }^{27}$ and social, cognitive, emotional and behavioural outcomes ${ }^{28}$ in offspring make heavy gestational alcohol consumption a high public health priority. Additionally, since most women who consume alcohol do so at lower levels where the offspring growth ${ }^{29}$ and development effects are less well understood, ${ }^{30}$ the widespread consumption of even low levels of alcohol during 
pregnancy is a significant public health concern. As we do not find compelling evidence that alcohol use is more prevalent in any particular sociodemographic group, for example, in single or less well educated women which were also shown in a recent systematic review to be inconsistently related to alcohol use during pregnancy, ${ }^{31}$ healthcare professionals should continue to advise all pregnant women to abstain from alcohol during pregnancy in line with best practice clinical care guidelines, irrespective of professionally perceived risk of exposure. Given evidence of higher risk of drinking during pregnancy among smokers which was consistent across cohorts and within countries examined, and which is also consistent with recent evidence of increased drinking among smokers in other cohorts, ${ }^{32-}$ 34 dual targeting of smoking and alcohol consumption should potentially be increased and delivered routinely upon a woman's indication of either behaviour during pregnancy. New policy and interventions are also required to reduce alcohol prevalence both prior to and during pregnancy.

This cross-cohort comparison highlights the urgent need for a biological marker of gestational alcohol use, since it is difficult to estimate to what extent estimates and their predictors are plausible even in more robust study designs (prospective measurement being the most superior), and when data is analysed in a comparative design such as ours. Additionally, this research highlights the need for a clear convention and standard method of measurement of alcohol use across observational studies which minimises heterogeneity in measurement, insofar as is possible using self-reported measurement of socially undesirable behaviours. Population differences in actual alcohol consumption are a plausible reason for variation in prevalence. However, variation in measurement methods may also explain differing prevalence and predictors, such as differences in interviewing techniques of SCOPE midwives across centres. Another potential reason for variation in reporting, or indeed actual alcohol use, may include variation in professional and patient attitudes to the acceptability of alcohol consumption during pregnancy, such that propensity to report alcohol use or consume alcohol during pregnancy would be easily influenced by a combination of measurement method, cultural attitudes to alcohol and social desirability, thereby underscoring the need for objective measures of gestational alcohol use.

\footnotetext{
Author affiliations

${ }^{1}$ National Perinatal Epidemiology Centre, Cork University Maternity Hospital, Wilton, Cork, Ireland

${ }^{2}$ Department of Epidemiology and Public Health, University College Cork, Cork, Ireland

${ }^{3}$ The Irish Centre for Foetal and Neonatal Translational Research (INFANT), University College Cork, Cork, Ireland

${ }^{4}$ Department of Obstetrics and Gynecology, University College Cork, Cork, Ireland

${ }^{5}$ Division of Women's Health, Women's Health Academic Centre, King's

College London, and King's Health Partners, London, UK
}

${ }^{6}$ Department of Obstetrics and Gynaecology, Faculty of Medical and Health Sciences, South Auckland Clinical School, University of Auckland, Auckland, New Zealand

${ }^{7}$ National Centre for Growth \& Development and Maternal and Fetal Health, Liggins Institute, University of Auckland, Auckland District Health Board and Counties Manukau District Health Board, Auckland, New Zealand

${ }^{8}$ Women's and Children's Division Lyell McEwin Hospital, University of Adelaide, Adelaide, South Australia

${ }^{9}$ St James University Hospital, Leeds, UK

${ }^{10}$ Department of Obstetrics and Gynaecology, Faculty of Medical and Health Sciences, University of Auckland, Auckland, New Zealand

Contributors LMO'K had the original idea for the study, wrote the first draft of the article, applied critical revisions to the article based on other coauthor recommendations, and approved the final version for publication. PMK, FM and ASK conceptualised the design of the study with other coauthors, assisted in interpretation of the data, reviewed and revised the manuscript and approved the final version for publication. RAG conceptualised the design of the study, assisted in the interpretation of the data, contributed to critical revisions of the article, and approved the final version for publication. RAN, LP, LMEM, PNB, GAD, JJW and RT conceptualised the design of the study, contributed to critical revisions of the article and approved the final version for publication. LCK supervised the write up of the manuscript, contributed to critical revisions of the article and approved the final version for publication.

Funding The New Zealand SCOPE study was funded by the New Enterprise Research Fund, Foundation for Research Science and Technology; Health Research Council (04/198); Evelyn Bond Fund, Auckland District Health Board Charitable Trust. The Australian SCOPE study was funded by the Premier's Science and Research Fund, South Australian Government (http://www.dfeest. sa.gov.au/science-research/premiers-research-and-industry-fund). The Irish SCOPE study was funded by the Health Research Board of Ireland (CSA/2007/2) (http://www.hrb.ie). The UK SCOPE study was funded by National Health Service NEAT Grant (Neat Grant FSD025), Biotechnology and Biological Sciences Research council (http://www.bbsrc.ac.uk/funding) (GT084) and University of Manchester Proof of Concept Funding (University of Manchester); Guy's and St Thomas' Charity (King's College London) and Tommy's charity (http://www.tommys.org/) (King's College London and University of Manchester); and Cerebra UK (http://www.cerebra.org.uk) (University of Leeds). The Growing Up in Ireland study is funded by the Government of Ireland through the Department of Children and Youth Affairs in association with the Department of Social Protection and the Central Statistics Office. PRAMS was conducted with both the administrative and financial support of the National Perinatal Epidemiology Centre, Cork and staff of Cork University Maternity Hospital and with assistance from Health Research Board (HRB) in Ireland (grant no PHD/2007/16).

\section{Competing interests None declared}

Ethics approval Ethical approval for GUI was provided by an independent research ethics committee convened by the Department of Health and Children in Ireland especially for the GUI study. Ethical approval for PRAMS was received from the Clinical Research Ethics Committee of the Cork Teaching Hospitals. Ethical approval for SCOPE was obtained from local ethics committees (New Zealand AKX/02/00/364, Australia REC 1712/5/2008, London and Manchester 06/MRE01/98 and Cork ECM5 (10)05/02/08).

Provenance and peer review Not commissioned; externally peer reviewed.

Data sharing statement No additional data are available.

Open Access This is an Open Access article distributed in accordance with the Creative Commons Attribution Non Commercial (CC BY-NC 4.0) license, which permits others to distribute, remix, adapt, build upon this work noncommercially, and license their derivative works on different terms, provided the original work is properly cited and the use is non-commercial. See: http:// creativecommons.org/licenses/by-nc/4.0/

\section{REFERENCES}

1. Ministry of Health. Alcohol and pregnancy: a practical guide for health professionals. Wellington: Ministry of Health, 2010.

2. Health Services Executive Ireland (HSE). Alcohol and pregnancy, 2009. http://www.yourdrinking.ie/alcohol-and-pregnancy 
3. Butt P, Beirness D, Gliksman L, et al. Alcohol and health in Canada: a summary of evidence and guidelines for low risk drinking. Ottawa: Canadian Centre on Substance Abuse, 2011.

4. Department of Health and Human Services. U.S. surgeon general releases advisory on alcohol use in pregnancy, 2005. http://www. surgeongeneral.gov

5. National Institute for Care and Clinical Excellence (NICE). Antenatal care: routine care for healthy pregnant women: NICE clinical guidelines 62, 2008.

6. Kelly $\mathrm{Y}$, lacovou M, Quigley $\mathrm{M}$, et al. Light drinking versus abstinence in pregnancy-behavioural and cognitive outcomes in 7-year-old children: a longitudinal cohort study. BJOG 2013:120:1340-7

7. Sayal K, Draper ES, Fraser R, et al. Light drinking during pregnancy and mid childhood mental health and learning outcomes. Arch Dis Child 2013;98:107-11.

8. Quail A, Williams J, McGrory C, et al. A summary guide to wave 1 of the infant cohort (at 9 months) of Growing up in Ireland, 2011.

9. Quail A, Williams J, McGrory C, et al. Questionnaires for wave 1 of the infant cohort (at 9 months) of Growing up in Ireland, 2011.

10. McCowan LME. Spontaneous preterm birth and small for gestational age infants in women who stop smoking early in pregnancy: prospective cohort study. BMJ 2009;338:1081-2009.

11. O'Keeffe LM, Kearney PK, Greene RA. Surveillance during pregnancy: methods and response rates to a hospital based cross sectional study of the Pregnancy Risk Assessment Monitoring System in Ireland. BMC Pregnancy Childbirth 2013;13:180.

12. North RA, McCowan LM, Dekker GA, et al. Clinical risk prediction for pre-eclampsia in nulliparous women: development of model in international prospective cohort. BMJ 2011;342:1875.

13. MedSciNet. MedSciNet. Secondary MedSciNet, 2014. http:// medscinet.com

14. Centres for Disease Control and Prevention (CDC). PRAMS model protocol 2009 version. Atlanta: Centres for Disease Control and Prevention, Georgia, 2009

15. O'Keeffe LM, Kearney PM, Greene RA. Pregnancy risk assessment monitoring system in Ireland: methods and response rates. Matern Child Health J 2015;19:480-6.

16. McCarthy FP, O'Keeffe LM, Khashan AS, et al. Association between maternal alcohol use during pregnancy and pregnancy outcomes. Obstet Gynecol 2013;122:830-7.

17. Jacobson SW, Chiodo LM, Sokol RJ, et al. Validity of maternal report of prenatal alcohol, cocaine, and smoking in relation to neurobehavioral outcome. Pediatrics 2002;109:815.

18. Mullally A, Cleary BJ, Barry J, et al. Prevalence, predictors and perinatal outcomes of peri-conceptional alcohol exposureretrospective cohort study in an urban obstetric population in Ireland. BMC Pregnancy Childbirth 2011;11:27.
19. Bakker R, Pluimgraaff LE, Steegers EA, et al. Associations of light and moderate maternal alcohol consumption with fetal growth characteristics in different periods of pregnancy: the Generation R Study. Int J Epidemiol 2010;39:777-89.

20. Andersen AMN, Andersen PK, Olsen J, et al. Moderate alcohol intake during pregnancy and risk of fetal death. Int J Epidemiol 2012;41:405-13.

21. Nykjaer C, Alwan NA, Greenwood DC, et al. Maternal alcohol intake prior to and during pregnancy and risk of adverse birth outcomes: evidence from a British cohort. J Epidemiol Community Health 2014;68:542-9.

22. Stommel M, Wills C. Clinical research: concepts and principles for advanced practice nurses. Philadelphia: Lippincott Williams \& Wilkins, 2004.

23. Colvin L, Payne J, Parsons D, et al. Alcohol consumption during pregnancy in nonindigenous west Australian women. Alcohol Clin Exp Res 2007;31:276-84.

24. Counsell A, Smale P, Geddis D. Alcohol consumption by New Zealand women during pregnancy. N Z Med J 1994;107:278.

25. Hutchinson D, Moore EA, Breen C, et al. Alcohol use in pregnancy: prevalence and predictors in the longitudinal study of Australian Children. Drug Alcohol Rev 2013;32:475-82.

26. O'Leary CM. The association between prenatal alcohol exposure, fetal growth and preterm birth: evidence from a systematic review and meta-analyses. Evid Based Nurs 2012;15:77-8.

27. Lucas BR, Latimer J, Pinto RZ, et al. Gross motor deficits in children prenatally exposed to alcohol: a meta-analysis. Pediatrics 2014;134: e192-209.

28. Irner TB. Substance exposure in utero and developmental consequences in adolescence: a systematic review. Child Neuropsychol 2012;18:521-49.

29. Hendersen J, Gray R, Brocklehurst P. Systematic review of effects of low-moderate alcohol exposure on pregnancy outcome. BJOG 2007:114:243-52

30. O'Keeffe LM, Greene RA, Kearney PM. The effect of moderate gestational alcohol consumption on speech and language outcomes in children: a systematic review. Syst Rev 2014;3:1.

31. Skagertróm J, Chang G, Nilsen P. Predictors of drinking during pregnancy: a systematic review. J Womens Health 2011;20:901-13.

32. Hutchinson D, Moore EA, Breen C, et al. Alcohol use during pregnancy: prevalence and predictors in a longitudinal study of Australian children. Drug Alcohol Rev 2011;32:475-82.

33. Powers JR, McDermott LJ, Loxton DJ, et al. A prospective study of prevalence and predictors of concurrent alcohol and tobacco use during pregnancy. Matern Child Health J 2013;17:76-84.

34. Walker MJ, Al-sahab B, Islam F, et al. The epidemiology of alcohol utilisation during pregnancy: an analysis of the Canadian Maternity Experiences Survey (MES). BMC Pregnancy Childbirth 2011;11:52. 